\title{
My Journey from the Inner-City to Medical School
}

\author{
Mateen Akhtar \\ Faculty of Medicine, University of Ottawa, Ottawa, Ontario, Canada
}

ABSTRACT

As an immigrant who grew up in the inner-city Toronto and Hamilton community to a low income family, this article highlights some of the challenges faced by me and countless other students living in these communities on their route to pursuing a career in medicine. While becoming a physician requires many things including academic excellence, growing up in these circumstances is filled with challenges that extend far beyond the classroom. More specifically, a lack of mentorship, experience, and financial resources disadvantage marginalized students' medical school applications and subsequently might impede them from pursuing a career as a physician.

RÉSUMÉ

En tant qu'immigrant ayant grandi dans les quartiers urbains défavorisés de Toronto et de Hamilton, au sein d'une famille à faible revenu, cet article met en lumière certains des défis auxquelsj'ai, moi-même, été confronté, mais aussi ceux auxquels d'innombrables autres étudiants vivant dans ces communautés font face lorsqu'ils décident de poursuivre une carrière en médecine. Bien que devenir médecin exige beaucoup de choses, y compris l'excellence académique, grandir dans ces circonstances est rempli de défis qui vont bien au-delà de la salle de classe. Plus précisément, le manque de mentorat, d'expérience et de ressources financières désavantagent les étudiants marginalisés à poser leur candidature aux écoles de médecine et pourrait donc ultérieurement les empêcher de poursuivre une carrière en tant que médecin.

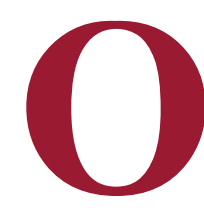
n October 8th 1989, I was born on the outskirts of rural Lahore, Pakistan. As a child, I grew up in a part of the world where major illness and death are commonplace. My mother, a physician, ignited my passion to be a part of the healthcare profession as I observed her struggle to serve those living in one of the most medically-underserved parts of the world. At the age of 8 , my family and I left Pakistan for Canada to start a new life. My parents along with my older brothers and I first moved to a one-bedroom apartment in the Thorncliffe Park neighbourhood in Toronto where nearly $50-53 \%$ of children live below the low income cut-off, which is calculated in 2016 as $\$ 20,386$ for one person or $\$ 38,544$ for a family of four after taxes (1). As new immigrants, my parents had a difficult time finding work related to their previous academic and professional training in Pakistan as it was not recognized. Thankfully, after an exhaustive search, my dad was fortunate in getting a factory job in Hamilton and moved our family accordingly. I spent the next few years of my life living in the inner-city Jamesville community in Hamilton where the majority of residents are visible minorities, where students are twice as likely to not finish high school when compared to the rest of the city, and where almost half of all children live in poverty (2). In addition, the residents of Jamesville were much less likely to have a family doctor, had a higher rate of emergency room visits, and had a lower life expectancy than the average Hamilton resident (2). While the relationship between poverty, education, and life expectancy is complex; one plausible explanation could be that living in these impoverished communities increases the likelihood that individuals might participate in health deteriorating behaviors such as substance abuse which could increase the risk of developing diseases that can cause premature mortality. As a child, I was oblivious to the realities of these neighbourhoods, and it is only as an adult that I am able to reflect back on and truly appreciate the dire circumstances my family endured and how incredibly thankful I am to be studying medicine at the University of Ottawa despite this upbringing.

A few years after moving to Hamilton, my dad was unfortunately laid off his factory job. As the main breadwinner of our family, he had a difficult time finding another job given his age and physical limitations. Despite my family's continued financial struggles, I was fortunate to be starting my first undergraduate degree at McMaster University in Kinesiology through government student loans. At this point in my life, I was unclear about what career path I wanted to follow, I did not have any mentors that I could reach out to for help, and I certainly had no idea of what the requirements were for getting into medical school. All I knew is that I had

Keywords: Medical school, medical school applications, medical education, undergraduate 
a passion for helping others. Shortly after completing my first undergraduate degree, I wanted to help my family financially and began working at the Wharton Internal Medicine Clinic located in the heart of inner-city Hamilton. At this clinic, I was a part of an interdisciplinary healthcare team that designed a comprehensive lifestyle intervention program catered specifically to the needs of patients with chronic health conditions which are often exacerbated by a mixture of physiological, psychological, and sociological factors. Specifically, this clinical experience instilled in me the importance of displaying an empathetic attitude towards all patients, especially those who are marginalized. By actively interacting with these patients and their family members on a regular basis, I have had the opportunity to see the real face of medicine, its frustrations and above all, its joys. This clinical experience helped me recognize how rewarding interacting with patients can be on a daily basis and ultimately convinced me that becoming a physician was the right career path for me.

The combination of my personal, educational, and professional experiences motivated me to take the next logical step in pursuing a career in healthcare by applying to medical schools. Upon critically reflecting on my potential application for medical schools, I was certain that admission into a Canadian medical school at this time was unlikely given the grades of my first undergraduate degree, and my best chance of studying medicine would have to be abroad, which could potentially allow me to return to Canada for residency training in the future. Unfortunately, due to the fact that my family is classified as low income, my professional line of credit application to help finance my international medical education was denied by every single major bank in Canada. I acknowledge these rejections as a major turning point in my life; I decided to use this time to revaluate, and ultimately, refocus my attention on doing everything necessary to gain admission into a Canadian medical school. While my family's financial status restricted my opportunities, the affluent familial financial status of many other applicants is considered a strong predictive factor for admission into medical school (3). More specifically, an affluential familial background benefits prospective medical students by allowing them to take preparatory courses for the MCAT which allows them to score higher, hiring personal tutors to assist them with individual prerequisite courses for medical school, increasing the likelihood they personally know a recent or current medical student that can guide them through the nuisances of applying to medical schools, being able to finance international medical education options without the need of a professional line of credit, and etc. The combination of these factors and many more allows prospective medical students from affluent backgrounds to obtain a very competitive medical school application which increases their likelihood of admission. As a result, it is estimated that $52 \%$ of medical students in Canada come from households that make over $\$ 100,000$ annually, which represents only $23 \%$ of Canadian households (4). On the other hand, only $15.4 \%$ of Canadian medical students come from a household income of less than $\$ 40,000$, which represents roughly $39.7 \%$ of all Canadian households (5). In addition, Black and Hispanic medical students in the United States of America were also three times as likely to come from a familial income of less than $\$ 50,000$ than their white colleagues (6). Thus, it became clear to me that it was more than just my grades that were potentially working against me on my journey to becoming a physician.

I continued on my journey to becoming a physician by enrolling into and completing the Master of Science in Global Health program at McMaster University which emphasised providing care to vulnerable populations around the world. However, even after completing an undergraduate and graduate degree, I understood my journey was far from complete and I needed to remain steadfast in reaching my goal. Accountability is a core competency of medicine, and I will be the first to admit that my academic performance of my first undergraduate degree was mediocre at best and I take complete responsibility for that. I knew that in order to be considered as a competitive applicant for Canadian medical schools, I would have to increase my undergraduate academic performance. Thus, I continued on my journey by completing a second undergraduate degree in Life Sciences at McMaster University with a near perfect GPA all while working to financially assist my family. Altogether, I had completed 6 years of full time undergraduate study, 2 years of part time undergraduate study, and 1 year of full time graduate study before my application for Canadian medical schools was deemed competitive.

On May 8th 2018, I was extremely fortunate in gaining admission into the University of Ottawa to study medicine. As an aspiring physician, I would love to make a positive impact on the lives of not only patients, but the community as a whole. In the future, I will focus my attention on communities where there appear to be a lack of medical facilities, so that vulnerable populations who are most in need of medical care are able to access it. Moving forward, it is important for medical schools across Canada to encourage applications from and subsequently matriculate marginalized students as the communities they come from tend to have some of 
the worst health outcomes in Canada. By doing so, medical students from marginalized backgrounds will be more likely to relate to marginalized patients and subsequently will be able to build a stronger physician-patient relationship, which is one of the most important steps necessary in reducing the burden of disease in these communities (6). More specifically, a recent study found that increasing the number of Black medical students and physicians in the United States of America could help to reduce the national disparity between black men and white men in cardiovascular mortality by $19 \%$ (7). Furthermore, a simple way to encourage applicants from marginalized communities is to have academic health centers provide financial, educational, and healthcare resources for the residents that live in these communities (6). One specific example of such as a strategy has been implemented by Southern Illinois University School of Medicine which has mentored more than 1000 disadvantaged youth since 1972 who have subsequently matriculated into its own medical or dental school (6). In addition, medical schools that take an holistic approach to admissions which emphasises an applicant's background, experiences, and challenges on their journey to medical school in addition to academic excellence reported an increase in diversity amongst their medical students (8). As a whole, by using an holistic approach to admissions and by building partnerships with local marginalized communities, medical schools can help to increase the diversity of their medical student population which can subsequently allow them to move one step closer to successfully fulfilling their societal obligation by caring for the wellbeing of all members of society.

\section{REFERENCES}

1. Neighbourhood Profile: Thorncliffe Park [Internet]. Toronto (ON): Social Policy, Analysis \& Research of Toronto; 2016 [cited 2019 August 1]. Available from: https://www.toronto.ca/ext/sdfa/Neighbourhood\%20 Profiles/pdf/2016/pdf1/cpa55.pdf

2. Mayo S, Klassen C, Bahkt L. Neighbourhood Profiles: Beasley, Crown Point, Jamesville, Keith, Landsdale, McQuesten, Quigley Road, Riverdale, Rolston, South Sherman, and Stinson [Internet]. Hamilton (ON): Social Planning and Research Council of Hamilton; 2012 [Cited 2019 August 1]. Available from: http://www.sprc.hamilton.on.ca/wp-content/uploads/2012/03/2012Report-Neighbourhood_Profiles_March.pdf

3. Barber M. How the medical school admissions process is skewed [Internet]. Toronto (ON):University Affairs; 2016 [cited 2019 August 1]. Available from: https://www.universityaffairs.ca/features/feature-article/medicalschool-admissions-process-skewed//

4. Walji M. Diversity in medical education: data drought and socioeconomic barriers. Can Med 173 Assoc J. 2015 Jan 6;187(1):11-11.

5. Dhalla IA, Kwong JC, Streiner DL, Baddour RE, Waddell AE, Johnson IL. Characteristics of first-year students in Canadian medical schools. CMAJ. 2002 Apr 16;166(8):1029-35.

6. Talamantes E, Henderson MC, Fancher TL, Mullan F. Closing the Gap Making Medical School Admissions More Equitable. N Engl J Med. 2019 Feb 28;380(9):803-5.
7. Marcella Alsan, Garrick O, Graziani G. Does Diversity Matter for Health? Experimental Evidence from Oakland. [Internet]: National Bureau of Economic Research; 2018 [Cited 2019 October 1]; Available from: https:// www.nber.org/papers/w24787.pdf

8. Drees B, Nairn R, Nivet M, Danek J, Glazer G, Bankston K. Holistic admissions in the health professions: findings from a national survey [Internet]: Urban Universities for Health;2014 [Cited 2019 October 1]. Available from: https://urbanuniversitiesforhealth.org/media/documents/Holistic Admissions_in_the_Health_Professions_final.pdf 